\title{
КОРРЕЛЯЦИЯ ПУБЛИЧНЫХ И ЦИВИЛИСТИЧЕСКИХ ФОРМ ВИНЫ
}

\begin{abstract}
Аннотация. В статье обосновываются избирательные правила квалификации вины, установленные применительно к обязательствам вследствие причинения вреда в цивилистическом законодательстве и присущие также административным правонарушениям. В отличие от публичных деликтных отношений квалификация виновного цивилистического правонарушения не совместима с атрибутами презумпции невиновности и, прежде всего, с возложением на публичных должностных лиц бремени доказывания вины. Квалификация признаков виновного деяния физического лица применительно к цивилистическим деликтам и административным правонарушениям сопряжена с установлением психологических критериев вины в виде умысла и неосторожности, однако в отличие от административной ответственности дефиниции умысла и неосторожности отсутствуют. Новизна статьи состоит в том, что в ней сделан выводо том. что квалификация неосторожного деяния с признаками "грубой неосторожности» применительно к цивилистической ответственности достаточно распространена, что особенно очевидно в сравнении с административной ответственностью, которая не индивидуализирует формы неосторожной вины, в отличие от уголовной ответственности с ее строгой формализацией атрибутов неосторожного деяния. В процессе исследования применялись общефилософский, теоретический, общефилософские методы (диалектика, системный метод, анализ, синтез, аналогия, дедукция, наблюдение, моделирование), традиционно правовые методы (формально-логический), а также методы, используемые в конкретно-социологических исследованиях. В статье доказано, что презумпция объективного вменения деликта представляет собой исключительное явление, присущее только цивилистической ответственности. Кроме того в работе обосновывается вывод о тождестве субъективных критериев корпоративной вины, установленных ГК и КоАП РФ, а также юридически значимых обстоятельств непреодолимой силы, крайней необходимости и необходимой обороны. Гражданско-правовая санкция в отличие от публичной санкции не является наказанием и не преследует достижения превентивных целей.
\end{abstract}

Ключевые слова: деликт, правонарушение, корреляция, публичный, частный, санкция, наказание, ответственность, право, закон.

Abstract. The article substantiates the specific rules of guilt qualification in the cases of infliction of harm according to civilized and administrative legislation. Unlike public delictual relations, the qualification of a guilty civilized offence doesn't comply with the assumption of innocence attributes, and especially with the imposition of the burden of evidence on public officials. The qualification of a guilty act of a person in relation to civilized delicts and administrative offences is connected with detecting the psychological criteria of guilt in the form of a guilty intent or negligence, but, unlike the administrative responsibility cases, there are no definitions of a guilty intent or negligence. The author concludes that the qualification of a negligent act with the signs of "gross carelessness" in relation to civilized responsibility is widely spread. It is noticeable in comparison with administrative responsibility which doesn't individuate the forms of negligence, unlike criminal responsibility characterized by the formalization of attributes of negligence. The author applies general philosophical and theoretical methods (dialectics, the system method, analysis, synthesis, analogy, deduction, observation and modeling), traditional legal methods (formal logical) and the methods of special sociological research. The author proves that the presumption of objective imputation of delict is a specific phenomenon typical only for civilized responsibility. Besides, the author substantiates the conclusion about the identity of subjective criteria of corporate guilt, established by the Civil Code and the Administrative Offences Code, and the legally important circumstances of force majeure, extreme necessity and necessary defence. A civil sanction, unlike a public one, is not a punishment and doesn't have preventive purposes.

Key words: responsibility, punishment, sanction, private, public, correlation, offence, delict, right, law.

Ц ивилистическая ответственность отличается от публичной ответственности особенностями квалификации вины. Совершение виновного правонарушения по общему правилу обязательственного права является необходимой предпосылкой квалификации вины, за исключением обязательств, обусловленных неосновательным обогащением, а также в тех случаях, когда федеральным законом или гражданско-правовым договором прямо предусмотрено объективное вмене- 


\section{Административное и муниципальное право 9 (105) • 2016}

ние (см. ч. 1 ст. 401, п. 2 ст. 1102 ГК). Избирательные правила квалификации вины установлены применительно к обязательствам вследствие причинения вреда. В отношении таких обязательств объективное вменение допускается только в случаях, прямо предусмотренных цивилистическим предписанием федерального закона, но не договором, как это установлено общими правилами обязательственного права (ср. абз. 1 п. 1 ст. 401 и п. 2 ст. 1064 ГК). Объективное вменение правонарушения предусмотрено в отношении отдельных из рассматриваемых обязательств, например, применительно к возмещению вреда, причиненного вследствие недостатков товара, работы или услуги (см. абз. 1 ст. 1095 ГК). При квалификации правонарушения, обусловленного неосновательным обогащением, не принимаются во внимание психологические критерии вины физического лица, применительно к ним не учитывается волевая, целенаправленная направленность вредоносных действий (см. п. 2 ст. 1102 ГК), что свидетельствует и о применении квалифицирующих признаков объективного вменения также и в этих случаях [1].

В отличие от публичных деликтных отношений квалификация виновного цивилистического правонарушения несовместима с атрибутами презумпции невиновности, во всяком случае с основным из них, а именно - с возложением на публичных должностных лиц бремени доказывания вины. Общие правила обязательственного права возлагают на лицо, подозреваемое в совершении деликта, подтверждение своей невиновности (см. п. 2 ст. 401, п. 2 ст. 1064, п. $1-3$ ст.1073, п. 1 ст. 1076, п. 2 ст. 1079 ГК).

Для цивилистических правонарушений характерны присущие только им атрибуты квалификации индивидуальной и корпоративной вины.

Квалификация признаков виновного деяния физического лица сопряжена с установлением психологических критериев вины в виде умысла и неосторожности (абз. 1 п. 1 ст. 401 ГК). Однако в отличие от аналогичных публично-правовых критериев индивидуальной вины они не рассматриваются в качестве основополагающего правового института, во всяком случае дефиниции умысла и неосторожности отсутствуют, что означает квалификацию вины исключительно по усмотрению судьи.

В отличие от публичных правонарушений при установлении критериев неосторожного деликта учитываются квалифицирующие признаки т.н. «грубой неосторожности» (п. 4 ст. 227, п. 1 ст. 693, ст. 697 , п. 1,2 ст. 901 , абз. 2 п. 1 ст. 963, п. 2 ст. 1083, п. 2 ст. 1104 ГК). Применительно к психологическим критериям вины, определенным п. 1 ст. 401 ГК, атрибуты неосторожного деяния отождествляются ГК именно с признаками «грубой неосторожности». Квалификация этой формы вины сопряжена с установлением противоправных действий физического лица, пренебрежительно относящегося как к самому асоциальному действию, так и к его особо вредоносным последствиям, обусловленным причинением реального или потенциального имущественного ущерба, физического (телесного), морального или репутационного вреда.

Признаки «грубой неосторожности» устанавливаются судьей применительно к конкретному цивилистическому деликту и свидетельствуют об особой общественной опасности правонарушения, посягающего на значимые частноправовые и публичные имущественные интересы.

Гражданско-правовой ответственности присуща особая избирательность форм индивидуальной вины. Квалификация неосторожного деяния с признаками «грубой неосторожности» применительно к цивилистической ответственности достаточно распространена, что особенно очевидно в сравнении с административной ответственностью / Прямое указание в КоАП на неосторожную вину как необходимый квалифицирующий признак проступка представляют собой достаточно редкое явление и предусмотрено главным образом при совершении правонарушений в сфере транспортной деятельности, а также при нарушениях ПДД (см. ч. 2 ст. $7^{15}$, ст. $9^{10}$, ч. 1,2 ст. 11.5 , ч. 1 ст. $11.15^{1}$, ч. 1 ст. $11.15^{2}$, ч. 2 ст. $11.15^{2}$, ч. 2 ст. 12.30 , ч. 1 ст. $19.7^{9}$ и ст. 19.16 КоАП)/, которая, как известно, не индивидуализирует форм неосторожной вины, в отличие от уголовной ответственности с ее строгой формализацией атрибутов неосторожного деяния (ср. ч. 2 ст. 2.2 КоАП РФ и ч. 1, 2 ст. 26 УК). Во многих случаях установление признаков деликта сопряжено только с выявлением вины в форме умысла (см. ст. 169, п. 2 ст. 406 , п. 1 ст. 578 , п. 4 ст. 720 , ст. 948 , п. 3 ст. 962 , п. 1 ст. 963 , п. 1 ст. 965, п. 3 ст. 1083 , п. 4 ст. 1090 , ст. 1108, п. 1 ст. 1117 ГК) или, как это было показано выше, в форме «грубой неосторожности».

В отличие от гражданско-правовых деликтов и административных проступков, установление квалифицирующих признаков деяний, совершенных по легкомыслию или небрежности, в тех случаях, когда выявление признаков неосторожного преступления является необходимой предпосылкой для его квалификации, представляет собой обыденное явление уголовно-процессуальной практики.

Подобная формализация психологических критериев вины в форме умысла и неосторожности сочетается в цивилистике с достаточно редкими предписаниями, устанавливающими обязательную квалификацию индивидуальной или 
корпоративной вины. Общая ответственность организаций и физических лиц при условии выявления признаков виновного деяния установлена только ст. 538 и п. 1 ст. $1253^{1}$ ГК, в остальных случаях обязательная квалификация деликта регламентирована избирательно, применительно к деяниям, совершенным юридическими лицами (п. 2 ст. 547 и ст. 1253) или публичными физическими лицами (п. 2 ст. 1070 и п. 3 ст. 1081 ГК).

Презумпция объективного вменения деликта представляет собой исключительное явление, присущее только цивилистической ответственности. Констатация объективного вменения гражданского правонарушения независимо от установления признаков вины предусмотрена п. 2 ст. 404, п. 2 ст. 1064 , п. 1 ст. 1070 , абз. 3 п. 2 ст. 1083, абз. 1 ст. 1095 , ст. 1100 , абз. 3 п. 3, п. 4 ст. 1250 ГК). Правила объективного вменения применяются как к индивидуальным, так и к корпоративным деликтам, причем в отношении отдельных цивилистических деликтов квалификация правонарушения независимо от вины не исключает исполнение нарушителем обязанностей, обусловленных минимизацией причиненного им имущественного ущерба, морального или репутационного вреда (см. п. 5 ст. 1250 ГК). В отличие от гражданско-правовой ответственности установление дополнительных обременений при совершении публичного правонарушения, в т.ч. и исполнения обязанностей, обусловленных фактом его совершения, возможно только в отношении виновного деяния (см. п. 4 ст. 4.1 КоАП РФ).

Правила избирательного применения признаков и форм виновного деяния в зависимости от существа правонарушения применяются также при квалификации взаимного (обоюдного) правонарушения, в случаях, когда его возникновение обусловлено обеими сторонами деликтного отношения (см. п. 1, 2 ст. 404 ГК). Указанные квалифицирующие признаки свойственны только правонарушениям обязательственного права и не применяются к публичным правонарушениям.

Применительно к корпоративному деяния установлены субъективные критерии вины, согласно которым юридическое лицо, подозреваемое в совершении деликта, обязано привести факты и обстоятельства, свидетельствующие о том, что им были приняты все меры для надлежащего соблюдения обязательства (см. абз. 2 п. 1 ст. 401 ГК) / В данном случае очевидны реминисценции с субъективными критериями корпоративной вины, установленными ч. 2 ст. 2.1 КоАП РФ/.

Надлежащее исполнение цивилистических прав и обязанностей в этих случаях сопряжено с точным соблюдением гражданско-правовых предписаний, пренебрежение которыми орга- низацией квалифицируется в качестве правонарушения, что свидетельствует о тождестве субъективных критериев корпоративной вины, установленных ГК и КоАП РФ (ср. абз. 2 п. 1 ст. 401 ГК и ч. 2 ст. 2.1 КоАП РФ).

Гражданское право устанавливает особые правила регламентации применительно к публичным и частноправовым корпоративным правонарушениям. Прежде всего различаются правонарушения публичного органа и публичной организации. Цивилистические правонарушения, совершенные федеральным органом исполнительной власти, подлежат возмещению за счет казны РФ (см. п. 9 ст. $8^{1}$, п. 7 ст. 51 ГК). Различия деликтов, совершенных публичной организацией, обусловлено существом правонарушения и значимостью причиненного им имущественного ущерба, морального, репутационного вреда (см. п. 2, 3 ст. 1073, абз. 2 п. 2 ст. 1074 ГК). Во всяком случае негативные последствия публичного корпоративного правонарушения более значимы и превышают размер имущественного ущерба, морального, репутационного вреда при совершении деликта частноправовой организацией (см. абз. 3 п. 3 ст. $67^{3}$ ГК).

Совершение правонарушения государственным органом или организацией в указанных случаях влечет за собой возмещение имущественного ущерба или компенсацию морального, репутационного вреда в соответствии с правилами, установленными административным законодательством, поскольку цивилистические предписания не применяются к публичным имущественным отношениям, обусловленным виновным правонарушением, совершенным органом исполнительной власти или публичной организацией (п. 3 ст. 2 ГК). Иные правовые последствия влекут за собой виновные гражданские правонарушения, совершенные частноправовой организацией, ущерб в этих случаях возмещается за счет корпоративного имущества (см. абз. 3 п. 3 ст. $67^{3}$ ГК). Подобные деликтные имущественные отношения не имеют публичноправовой основы, их возникновение не обусловлено властной соподчиненностью их участников и в этих случаях применяются гражданско-правовые предписания.

Свои особенности присущи также квалификации правонарушения, совершенного частноправовым и публичным физическим лицом. Вредоносность деликтов, совершенных должностным лицом частного или публичного права (см. соответственно абз. 1 п. 1, п. 3 ст. 53 ${ }^{1}$, п. 1 ст. 1070, ч. 3 ст. 1081 и п. 1 ст. $53^{1}$ ГК) несоизмерима с негативными последствиями деяния физического лица, не наделенного правомочиями должностного лица (см. п. 3 ст. 28, п. 3 ст. 230 ГК). Подтверждение судом статуса должностного лица и установление причин- 


\section{Административное и муниципальное право 9 (105) • 2016}

но-следственной связи совершенного им деликта с неисполнением возложенных на него обязанностей представляет собой важный атрибут квалификации вины должностного лица.

Применительно к другим признакам, необходимым для квалификации вины следует особо отметить установление судом юридических фактов, свидетельствующих о наличии юридически значимых обстоятельств непреодолимой силы, крайней необходимости и необходимой обороны. Вышеуказанные обстоятельства избирательно учитываются и в юрисдикционных действиях, связанных с квалификацией проступков и преступлений.

Обстоятельства непреодолимой силы следует рассматривать в качестве вариабельного признака, наличие таких обстоятельств несовместимо с квалификацией вины, либо оно не влияет на такую квалификацию в случаях, когда это предусмотрено федеральным законом или договором (см. п. 3 ст. 401 ГК), или применительно к нарушениям интеллектуальных прав, непосредственно ГК (см. абз. 3 п. 3 ст. 1250 ГК). Об избирательности применения фактов и обстоятельств непреодолимой силы при квалификации административных правонарушений свидетельствует и КоАП РФ, во всяком случае судья или юрисдикционный орган обязан учитывать наличие таких обстоятельств в процессе публичного доказывания вины, а также на стадии назначения административного наказания (см. ч. 2, 3 ст. 4.1, ч. 2, 3 ст. 4.2 КоАП РФ). Наличие таких обстоятельств имеет важное процессуальное значение при квалификации корпоративной вины, обусловленность проступка обстоятельствами непреодолимой силы несовместима с его вменением в ответственность.

Совершение гражданского правонарушения в состоянии крайней необходимости по общему правилу свидетельствует об отсутствии вины, во всяком случае причинитель вреда, представивший факты и обстоятельства, свидетельствующие о его причинении в состоянии крайней необходимости, не возмещает вред, что свидетельствует о его невиновности (см. п. 2 ст. 1064 и ст. 1066 ГК).

Совершение проступка в состоянии необходимой обороны может учитываться судьей в качестве обстоятельства, смягчающего административную ответственность, при этом не имеет никакого значения тот факт, что статус необходимой обороны КоАП не установлен / Лицо, совершившее правонарушение в состоянии необходимой обороны, в соответствии со ст. 19 Кодекса РСФСР об административных правонарушениях, не привлекалось к административной ответственности, что во всяком случае свидетельствует о значимости учета соответствующих фактов и обстоятельств также и применительно к юрис- дикционным действиям, установленным КоАП РФ/. Судья или юрисдикционный орган при возникновении таких обстоятельств могут использовать квалификацию таких обстоятельств ГК в качестве правоустанавливающего факта (см. п. 2 ст. 4.2 КоАП РФ).

Причинение вреда в состоянии крайней необходимости влечет за собой различные публичные и частноправовые последствия. Отсутствие признаков виновного цивилистического деяния, совершенного в состоянии крайней необходимости, не влияет на возмещение вреда. Причинитель вреда обязан его возместить даже в тех случаях, когда он устранял опасность, угрожающую ему самому или третьим лицам. Позитивные действия причинителя вреда, защищающего правоохраняемые публичные и частноправовые интересы, не влияют на существо деликтного отношения, несмотря на то, что такие действия не рассматриваются КоАП в качестве противоправных (ср. абз. 1 ст. 1087 ГК и ст. 2.7 КоАП).

При квалификации гражданского правонарушения принимается во внимание не только юридически формализованное деяние, но и правила делового обихода, моральные, нравственные правила, нарушение которых влечет за собой установление правоограничений или иные юридически значимые последствия. Нарушение «нравственных принципов общества» в соответствии с абз. 2 п. 3 ст. 1084 ГК влечет за собой отказ в возмещении вреда, причиненного правомерными действиями. Публичное право устанавливает юридически значимые атрибуты «правомерных действий», в случае, если такие действия сопряжены с реальным или потенциальным причинением вреда, они квалифицируются как противоправные. Цивилистическое законодательство различает публичные деликты, возникновение которых обусловлено правомерными и противоправными действиями органов государственной власти, муниципальных органов или их должностных лиц (см. ст. 16, 16루 абз. 1 п. 3 ст. 1064,1069 ГК).

Любые действия должностных лиц органов исполнительной власти, правоохранительных органов юридически формализованы в законах и подзаконных (в т.ч. ведомственных) нормативных правовых актах. Основное предназначение публичного и, прежде всего, административного законодательства заключено в создании надлежащих средств юридической защиты частноправовых лиц от властного произвола. Публичное должностное лицо вправе принимать юридически значимые действия только в тех случаях, когда они прогностически обоснованы и негативные последствия наступать не могут, в противном случае должностное лицо обязано воздержаться от осу- 
ществления потенциально вредоносных действий. Применение мер пресечения, административных наказаний и иных публичных санкций возможно только на основе предшествующей аналитической оценки неблагоприятных возможностей их применения. Таким образом, единственным критерием позитивной или негативной властной деятельности является ее реальная или потенциальная вредоностность, такую деятельность невозможно оценивать на основе абстрактных критериев «правомерности» и «противоправности»в тех случаях, когда действия публичных должностных лиц могут повлечь за собой причинение имущественного ущерба, телесного (физического), репутационного или морального вреда.

Основной критерий «правомерности» действий физического лица заключен в их «разумности и добросовестности» (ср. п. 3 ст. 53, абз. 2 п. 1, п. $2,3,5$ ст. $53^{1}$ ГК). Понятия, заимствованные цивилистическим законодательством из свода моральных и нравственных предписаний, зиждется на традициях правил делового обихода, присущих русскому гражданскому праву имперского периода развития, и ныне используются избирательно применительно к существу и предназначению конкретного отношения. Подтверждение «недобросовестных и неразумных» действий имеют важное значение для квалификации вины частноправового должностного лица. Как правило, эти нравственные понятия фиксируются в их взаимосвязи, однако имеются примеры и их изолированного применения, в тех случаях, когда существо правонарушения характеризуют только «недобросовестные» или «неразумные» действия нарушителя, рассматриваемые в деликтном единстве с «несправедливыми» действиями (ср. абз. 1 п. 5 ст. $53^{1}$, абз. 1 п. 2 ст. 1101 ГК).

Нравственная терминология гражданского законодательства модернизируется применительно к понятиям и определениям, заимствованным из политико-правового обихода и не имеющим ничего общего с традициями имперского гражданского права. Особую значимость для квалификации деликта имеет выявление противоправных признаков, посягающих на «нравственные принципы общества» и «противоречащих общественным интересам» (см. соответственно п. 3 ст. 1064 и абз. 2 п. 2 ст. 1065 ГК).

Общественно-политические термины и определения используются применительно к признакам корпоративного правонарушения, совершенного частноправовой организацией, в отличие от них понятия, заимствованные из свода нравственных цивилистических правил, характеризуют противоправную деятельность непубличных должностных лиц.
Использование нравственных и общественно-политических терминов и определений в правоприменительной, в т.ч. и юрисдикционной, деятельности сопряжено с объективными трудностями в силу их неконкретности и юридической бессодержательности. Формализованные требования, выражающие существо и предназначение терминов и определений в регламентации административного и иного публичного отношения, присущи исключительно публичной законотворческой деятельности и не используются применительно к гражданскому законодательству со свойственным ему заимствованием публичного понятийного аппарата. В отличие от дефиниций, характеризующих публичные имущественные отношения (см. ст. 242, 243 ГК), термины и определения деликтного права презюмируются применительно к соответствующим публично-правовым определениям (см. п.1 ст. 401, ст. 1066 ГК) либо, применительно к дефинициям корпоративной вины и грубой неосторожности, отсутствуют вовсе.

Термины и определения деликтного права в вышеуказанных случаях механически воспроизводят соответствующие публично-правовые определения, вуалируя тем самым адаптивность их применения в процессе регламентации конкретного деликтного отношения.

Гражданско-правовая санкция устанавливается за виновное, противоправное причинение вреда правоохраняемым интересам и заключается в ограничении имущественных прав нарушителя в объеме, соразмерном причинённому имущественному ущербу, моральному (репутационному) вреду. Предназначение цивилистической санкции в минимизации противоправных последствий деликта, в возмещении ущерба и компенсации вреда, причинённого правонарушением. Гражданскоправовая санкция в отличие от публичной санкции не является наказанием и не преследует достижения превентивных целей.

Цивилистическая санкция применяется по факту выявленного гражданского или публичного правонарушения. Атрибуты цивилистической ответственности присущи также и санкциям ad hoc, то есть наказаниям, установленным непосредственно гражданским законодательством.

Совершение публичного (подп. 1-4 п. 3 ст. 61 ГК) или цивилистического правонарушения (подп. 5 п. 3, п. 5, 6 ст. 61 ГК) влечет за собой применение санкции ad hoc в виде ликвидации юридического лица, применяемой судом по иску государственного (муниципального) органа.

Применение цивилистической санкции при совершении публичного правонарушения опосредовано возникновением изменением, приостановлением или прекращением административного от- 


\section{Административное и муниципальное право 9 (105) 2016}

ношения. В случаях нарушения регистрационного законодательства инициация административных процедур применения рассматриваемой санкции отнесена к ведению федеральных органов исполнительной власти, прежде всего федеральных служб, а также министерств РФ и федеральных агентств, наделенных правомочиями регистрирующего органа, либо (применительно к банковским организациям) Банка России (подп. 1 п. 3 ст. 61 ГК).

В тех случаях, когда санкции в виде ликвидации юридического лица предшествуют нарушения лицензионного законодательства, возбуждения административных процедур отнесено к ведению соответствующего лицензирующего органа. Такими правомочиями наделены федеральные органы исполнительной власти: федеральные службы, осуществляющие лицензирование по общему правилу, т.е. в соответствии с базовым Федеральным законом, а также министерства РФ или федеральные агентства, наделенные соответствующими правомочиями указами Президента РФ или постановлениями федерального Правительства.

Статусом лицензирующего органа наделяются также органы исполнительной власти субъектов Федерации, в случаях делегирования им лицензионных полномочий федеральным органом исполнительной власти.

Правомочия лицензирующего органа предоставлены также особым публичным субъектам Банку России, а также некоторым государственным корпорациям, наделённым таким статусом при делегировании им государственно-властных полномочий. / Такие правомочия предоставлены Государственной корпорации по атомной энергии «Росатом» и Государственной корпорации по космической деятельности «Роскосмос», после делегирования им компетенции упраздненных федеральных органов исполнительной власти Федерального агентства по атомной энергии и Федерального агентства по космической деятельности/.

Вышеуказанные публичные органы и организации вправе возбуждать процедуры ликвидации лицензиата - юридического лица в силу наделения их правомочиями лицензирующего органа и, прежде всего, правомочиями по применению публичных санкций в виде приостановления действий лицензии или инициации судебных процедур аннулирования лицензии. / Реализация государственной корпорацией, наделенной, как известно, правомочиями некоммерческой организации, функций искового производства по ликвидации лицензиата сопряжена с объективными правоприменительными трудностями, поскольку подп. 2 п. 3 ст. 61 ГК такие функции предоставлены только государственным или муниципальным органам/.
Применение цивилистической санкции в виде ликвидации юридического лица - лицензиата обусловлено нарушениями лишь отдельных лицензионных требований, а именно осуществлением безлицензионной деятельности, а также деятельности, не санкционированной саморегулируемой организацией, субъектом которой является лицензиат / См. подп. 2 п. 3 ст. 61 ГК и ст. 8 Федерального закона от 4 мая 2011 г. № 99-ФЗ «О лицензировании отдельных видов деятельности». В соответствии с п. 5 ч. 3 ст. 8 рассматриваемого федерального закона юридические факты, нарушение которых квалифицируется в качестве публичного правонарушения, согласно вышеуказанному предписанию ГК, следует рассматривать как нарушение лицензионных требований/.

Отдельные корпоративные правонарушения, влекущие ликвидацию юридического лица, охарактеризованы в обобщающем виде в качестве противоправной деятельности, «нарушающей законы и Конституцию РФ» (см. подп. 3 п. 3 ст. 61 ГК). Объективная сторона такого рода публичных правонарушений заключена в осуществлении так называемой «экстремистской деятельности», посягающей на основы государственного строя, общественный порядок и общественную безопасность. Объектом противоправных действий является также корпоративная деятельность, нарушающая порядок проведения общественно-политических мероприятий, декларированных ст. 31 Конституции РФ, формализованных федеральными законами и подзаконными актами.

Корпоративная деятельность, нарушающая нормы и правила, установленные двумя разновидностями подзаконных актов, а именно - указами Президента РФ и постановления федерального правительства (см. п. 6 ст. 3 и подп. 3 п. 3 ст. 61 ГК РФ) квалифицируются как противоправная и влечет за собой ликвидацию юридического лица - нарушителя по иску управомоченных федеральных органов исполнительной власти и правоохранительных органов.

Публичные корпоративные правонарушения, влекущие ликвидацию юридического лица, могут выражаться во внеуставной деятельности общественного объединения. Возбуждение дела о таком правонарушении возложено на органы юстиции, к ведению которых отнесена государственная регистрация общественных объединений и обеспечение последующего регистрационного контроля за их уставной деятельностью (см. подп. 4 п. 3 ст. 61 ГК). Объективная сторона такого рода правонарушений заключена в осуществлении общественным объединением коммерческой деятельности с последующим расходованием прибыли на цели, не предусмотренные уставом. В вышеуказанных 
случаях применению рассматриваемой цивилистической санкции предшествует выявление государственным органом факта публичного правонарушения.

Компетенция муниципальных органов, управомоченных инициировать процедуру ликвидации юридического лица, существенно ограничена. Исполнительно-распорядительные муниципальные органы вправе возбуждать дело только в отношении правонарушений, предусмотренных подп. 3 п. 3 ст. 61 ГК, совершенных организацией местного подчинения.

В редких случаях ликвидация юридического лица является следствием непубличного правонарушения, обусловленного ненадлежащим исполнением организацией уставных целей либо решения суда (см. соответственно подп. 5 п. 3, п. 5 ст. 61 ГК).

Установление признаков корпоративной вины представляет собой предпосылку квалификации публичного или цивилистического правонарушения, во всяком случае выявление признаков виновного деяния является необходимым условием квалификации деликта, совершенного публичной или непубличной организацией (см. соответственно п. 9 ст. $8^{1}$, п. 7 ст. 51 и абз. 3 п. 2 ст. $67^{3}$ ГК).

Установление признаков виновного деяния необходимо также в тех случаях, когда публичные правонарушения, влекущие за собой применение цивилистической санкции в виде ликвидации юридического лица, содержат признаки административного правонарушения. Безлицензионная корпоративная деятельность квалифицируется как публичное нарушение, предшествующее применению рассматриваемой гражданско-правовой санкции, и одноименно, как проступок, влекущий за собой применение административных наказаний (см. подп. 2 п. 3 ст. 61 ГК и ч. 2 ст. 14.1, ч. 1 ст. 19.20 КоАП РФ). Применительно к безлицензионной деятельности, в зависимости от существа правонарушения и особенностей причиненного им имущественного ущерба, морального, репутационного вреда, противоправное деяние влечет за собой ликвидацию организации либо применение административных наказаний, установленных вышеуказанными предписаниями КоАП РФ. В этих случаях публичное правонарушение, посягающее на общие правоохранительные интересы, влечет за собой применение различных санкций - рассматриваемой цивилистической санкции либо административных наказаний, при этом административные наказания несоизмеримы по своим правоограничительным последствиям с санкцией в виде ликвидации юридического лица.

Корреляция цивилистических санкций и административных наказаний возможна только применительно к минимизации вредоносных послед- ствий деяний. При совершении лицензионного правонарушения судья, одновременно с применением цивилистической санкции или административного наказания, при отсутствии спора принимает решение о возмещении имущественного ущерба либо инициирует судебные процедуры компенсации морального или репутационного вреда.

При совершении цивилистического правонарушения правила ГК о квалификации корпоративной вины применяются избирательно в зависимости от существа правонарушения и его вредоносных последствий. Цивилистическая санкция устанавливается судом за виновное противоправное деяние либо такая санкция применяется публичным органом на административной (бессудной) основе независимо от квалификации вины.

Публичная корпоративная санкция вменяется нарушителю в ответственность, устанавливаемые ею имущественные правоограничения не могут быть оспорены в суде.

Основанием для применения публичной санкции в виде сноса самовольной постройки является решение муниципального органа (п. 4 ст. 222 ГК). Такое решение неоспоримо и приводится в исполнение вынесшим его органом в уведомительном порядке.

Правомочия владельца, пользователя или собственника самовольной постройки прекращается в момент принятия муниципальным органом решения, подтверждающего самовольность постройки. Факт правонарушения, т.е. признание постройки самовольной, в данном случае презюмируется муниципальным органом на основе объективного вменения, никакие факты и обстоятельства, свидетельствующие о легитимном статусе постройки и законных правомочиях собственника, не принимаются во внимание.

Административное подтверждение факта правонарушения предопределяет и незаконность всех последующих действий застройщика, связанных с распоряжением объектом недвижимости (абз. 1 п. 2 ст. 222 ГК).

Муниципальный орган, управомоченный принудить застройщика (собственника) к сносу постройки либо снести ее самостоятельно, представляет собой доминирующую сторону деликтного отношения, пассивным участником которого является застройщик (собственник) объекта недвижимости. Правоустанавливающим решением применительно к подобным деликтным отношениям является административный акт публичного органа. Доминанта таких имущественных отношений - во властной соподчиненности их участников, определяющей сущность имущественного регулирования, предназначение которого в обеспечении публичных интересов. 


\section{Библиография:}

1. Куракин А.В. Актуальные проблемы административного права и процесса. - М., 2014. - С. 12.

2. Агапов А.Б. К вопросу о публичном принуждение в российском праве // NB: Административное право и практика администрирования. - 2013. - 7. - C. 58 - 87. DOI: 10.7256/2306-9945.2013.7.9922. URL: http://www.e-notabene. $\mathrm{ru} / \mathrm{al} /$ article_9922.html

3. Костенников М.В., Куракин А.В. Квопросу об основании административной ответственностив российскомправе // NB: Административное право и практика администрирования. - 2013. - 10. - С. 75 - 88. DOI: 10.7256/23069945.2013.10.10153. URL: http://www.e-notabene.ru/al/article_10153.html

4. Костенников М.В., Куракин А.В., Мышляев Н.П. Причины административных правонарушений // NB: Административное право и практика администрирования. - 2015. - 3. - С. 44 - 62. DOI: 10.7256/2306-9945.2015.3.15876. URL: http://www.e-notabene.ru/al/article_15876.html

5. Костенников М.В., Куракин А.В., Мышляев Н.П. Личность субъекта административного правонарушения // NB: Административное право и практика администрирования. - 2015. - 1. - С. 62 - 80. DOI: 10.7256/23069945.2015.1.15849. URL: http://www.e-notabene.ru/al/article_15849.html

\section{References (transliterated):}

1. Kurakin A.V. Aktual'nye problemy administrativnogo prava i protsessa. - M., 2014. - S. 12 .

2. Agapov A.B. K voprosu o publichnom prinuzhdenie v rossiiskom prave // NB: Administrativnoe pravo i praktika administrirovaniya. - 2013. - 7. - C. 58 - 87. DOI: 10.7256/2306-9945.2013.7.9922. URL: http://www.e-notabene.ru/al/ article_9922.html

3. Kostennikov M.V., Kurakin A.V. K voprosu ob osnovanii administrativnoi otvetstvennosti v rossiiskom prave // NB: Administrativnoe pravo i praktika administrirovaniya. - 2013. - 10. - C. 75 - 88. DOI: 10.7256/2306-9945.2013.10.10153. URL: http://www.e-notabene.ru/al/article_10153.html

4. Kostennikov M.V., Kurakin A.V., Myshlyaev N.P. Prichiny administrativnykh pravonarushenii // NB: Administrativnoe pravo i praktika administrirovaniya. - 2015. - 3. - C. 44 - 62. DOI: 10.7256/2306-9945.2015.3.15876. URL: http:// www.e-notabene.ru/al/article_15876.html

5. Kostennikov M.V., Kurakin A.V., Myshlyaev N.P. Lichnost' sub"ekta administrativnogo pravonarusheniya // NB: Administrativnoe pravo i praktika administrirovaniya. - 2015. - 1. - C. 62 - 80. DOI: 10.7256/2306-9945.2015.1.15849. URL: http://www.e-notabene.ru/al/article_15849.html 